\title{
Analysis of dyes in textiles from the Chehrabad salt mine in Iran
}

\author{
Chika Mouri ${ }^{1}$, Abolfazl Aali ${ }^{2}$, Xian Zhang $^{1}$ and Richard Laursen ${ }^{1 *}$
}

\begin{abstract}
This study describes the analysis of dyes from three textile specimens associated with human remains found in the Chehrabad salt mine in northwestern Iran dating to $2000 \pm 400$ years BP. They are unique for this part of the world not only because of their age, but because they represent textiles used by common people (salt miners) as opposed to funerary garments of the wealthy. Samples of yarns from these specimens were extracted and analyzed by high performance liquid chromatography with diode array and mass spectrometric detection. The red dye was obtained from madder (specifically Rubia tinctorum L.), and the blue was from an indigo plant, probably woad (Isatis tinctoria L.), both of which are known in Iran. Two yellow, plant-derived, flavonol dyes were found. The first seems to be from a species of tamarisk (Tamarix sp.), whereas the second, found in both yellow and green yarns, is from a so-far unidentified plant. This work represents the first detailed study of these salt mine dyes, and the first evidence for the use of tamarisk as a dyestuff.
\end{abstract}

Keywords: Salt mine; Textile; Dye analysis; Iran; Tamarix; Chehrabad; Sassnian; Achaemenid

\section{Introduction}

During the period 1993 - 2005, the mummified remains of several individuals were found in an ancient salt mine at Chehrabad, near Zanjan, in northwestern Iran [1]. These appear to be the remains of workers who were trapped or crushed by cave-ins some $2000 \pm 400$ years ago [1-3]. Because of the dryness of the site and the salty environment, these remains, as well as numerous other organic objects, including textile fragments, were well preserved. One unusual feature of the objects found at the Chehrabad salt mine is that they are associated with common people in their working environment. Most mummified remains, from Egypt, China and South America are of persons, generally of high status, who have been prepared for burial and often were clad in elaborate funerary garments. The Chehrabad mummies are of persons who died in their working clothes and could not be recovered for formal burial, and the other textiles found there presumably were lost or discarded by mine workers.

In this article we describe results of the first detailed analysis of dyes used to color some textiles found at the

\footnotetext{
* Correspondence: laursen@bu.edu

'Department of Chemistry, Boston University, Boston, MA 02215, USA

Full list of author information is available at the end of the article
}

Chehrabad site. Two of the dyes are unusual in that they seem to have come from plants never previously identified in dyed textiles.

\section{Materials and methods}

Textile and reference samples

Specimens of dyed woolen textiles from the Chehrabad salt mine were obtained from the Archaeological Museum of Zanjan, Iran.

Species of Tamarix were collected by botanists or the authors in the United States (Tamarix sp., Utah), Uzbekistan (Tamarix bungei Boiss., and an unidentified species of Tamarix) and China (Tamarix sp., Gansu Province). All others were obtained from the Harvard University Herbaria.

\section{Extraction of plant material and textile fibers}

Plant samples were extracted by heating about $10 \mathrm{mg}$ of the ground or chopped dry plant material with $1.0 \mathrm{~mL}$ of methanol/water $(1: 1)$ at $65^{\circ} \mathrm{C}$ for one hour. The mixtures were centrifuged in an Eppendorf model 5415 microcentrifuge at a nominal speed of 12,000 rpm for about $5 \mathrm{~min}$ and the supernatant liquid was removed by pipet and centrifuged again, after which the clear supernatant was subjected to analysis as described in the following section. 
These solutions were diluted with methanol/water (1:1) if necessary. In some cases, the plant extracts were heated with $\mathrm{HCl}$ to hydrolyze glycosidic and sulfate ester bonds to reveal the aglycones present.

Dyed textile or yarn specimens were extracted by heating $0.1-1 \mathrm{mg}(0.5-1 \mathrm{~cm})$ of yarn in $200 \mu \mathrm{L}$ of a solution of pyridine/water/1.0 $\mathrm{M}$ oxalic acid in water $(95: 95: 10)$ at $100^{\circ} \mathrm{C}$ for $15 \mathrm{~min}$, as described in detail in [4], or, in earlier studies, by heating with $5 \%$ formic acid in methanol at $60^{\circ} \mathrm{C}[5]$.

\section{Analysis of dye components}

Extracts of plant material or of dyed silk or wool were analyzed by high performance liquid chromatography (HPLC) with photodiode array and mass spectrometric detection using an Agilent 1100 high performance liquid chromatography system consisting of an automatic injector, a gradient pump, a Hewlett-Packard series 1100 photodiode array detector, and an Agilent series 1100 VL on-line atmospheric pressure ionization electrospray ionization mass spectrometer, essentially as described earlier [5]. Operation of the system and data analysis were done using ChemStation software, and detection was generally done in the negative ion $\left([\mathrm{M}-\mathrm{H}]^{-}\right)$mode, which gives less complex spectra, although the positive ion mode was sometimes used to reveal fragmentation patterns or for dyes, such as indigotin and indirubin, which do not give $[\mathrm{M}-\mathrm{H}]^{-}$signals. Separation of dye components was made, in the majority of cases, on various C18 reversed phase columns $(2.1 \mathrm{~mm}$ dia. $\times 250 \mathrm{~mm}$ long; $5-\mu \mathrm{m}$ particle size); in the earliest studies, a $\mathrm{C} 4$ reversed phase column was used. Columns were eluted with acetonitrile-water gradients containing $0.1 \%$ formic acid in both solvents. In the course of this work several gradients and columns were used, but because the types of stationary and mobile phases were unchanged, the elution times of peaks were generally in the same order. Gradient conditions for the most recent runs (36-min run; wateracetonitrile gradient) are given in Table1.

Some specimens were analyzed on Shimadzu LCMS2020 consisting of an automatic injector, a gradient pump, a diode array detector and a mass analyzer. Operation of the system and data analysis were done using LabSolution software, and detection was done in both the negative and

Table 1 HPLC gradient used to separate dye components

\begin{tabular}{ll}
\hline Time $(\boldsymbol{m i n})$ & Percent acetonitrile \\
\hline 0 & 16 \\
14 & 44 \\
22 & 95 \\
24 & 95 \\
25 & 16 \\
36 & 16 \\
\hline
\end{tabular}

the positive ion modes. Separation of dye components was made on a Phenomenex Luna C18 reversed phase column ( $2 \mathrm{~mm}$ dia. $\times 150 \mathrm{~mm}$ long; $3-\mu \mathrm{m}$ particle size), attached to a Phenomenex Security Guard column, and operated at a flow rate of $0.18 \mathrm{~mL} / \mathrm{min}$. Columns were eluted with acetonitrile-water gradients containing $0.1 \%$ formic acid, using essentially the same gradient as given above.

\section{Determination dye component structures}

Techniques and strategies for determining flavonoid structures have been described by Markham [6] and by us [7]. Structural assignments were inferred primarily from molecular mass measurements and UV-Visible spectral characteristics, as well as from $[\mathrm{M}+\mathrm{H}]^{+}$fragmentation patterns and from structures reported in the chemical literature. 3-O-substituted flavonols (e.g., quercetin and isorhamnetin) generally absorb maximally at around 350-354 $\mathrm{nm}$. The aglycones themselves, flavonols with unsubstituted 3-OH groups, generally have absorption maxima in the range $368-374 \mathrm{~nm}$.

\section{Results and discussion}

\section{Description of textile specimens}

The three textile fragments analyzed, and shown in Figure 1, here were not directly associated with specific mummified remains but were found, along with many other organic artifacts, scattered about the former salt mine. As discussed by Pollard et al. [3], the mine seems to have been worked in at least two periods, the Achaemenid (559 - 330 BCE) and the Sassnian (224 BCE - $651 \mathrm{CE})$. Three of the bodies found have been dated to about 400 $\mathrm{BCE}$ and may be the remains of miners killed in an earthquake-induced mine collapse at that time. The other human remains that have been dated are much later, probably between 100 and $500 \mathrm{CE}$. The textiles analyzed were not directly associated with any of the human remains and have not been radiocarbon dated, but stratigraphy suggests that two of them (nos. 10050 and 10141) are in the Sassnian layer and that no. 10031 is in the Achaemenid layer (Figure 1). It is probably safe to say is that they are in the range $2000 \pm 400$ years old.

All of the specimens analyzed were tabby woven wool. Specimen 10031 was all red, whereas the other two were woven from yarns of different colors. Specimen 10050 consists of a folded ribbon and may have served as a belt or rope. The yarn samples analyzed were taken from the upper left-hand corner of the object. The colored parts of specimen 10141 comprise a band on the edge of a mostly un-dyed object, perhaps a garment of some sort. This object has both blue and green areas, though only the continuous green stripe (left hand side in Figure 1) was analyzed. Both 10050 and 10141 have white portions, which appeared to be undyed because we could detect no colorants at all. The dyes found in the study are listed in Table 2. 

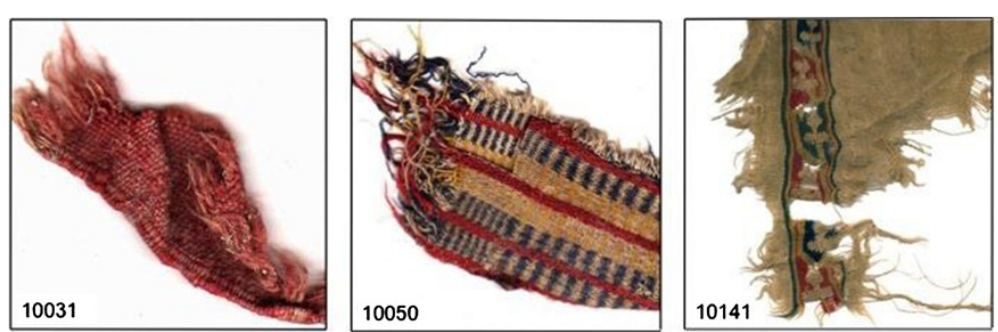

Figure 1 Photographs of textile specimens analyzed. Samples were taken from the upper left-hand corner of object 10050 and from the left-hand green stripe on object 10141.

\section{Red dye}

Analysis of the red-dyed yarns in all three specimens revealed primarily alizarin with traces of purpurin (see Figure 2). This indicates that the dye was derived from madder, specifically, Rubia tinctorum L., which was the predominant species used in Europe and Central Asia [8], so its presence in early Persian textiles is not surprising. We found no evidence for insect reds (e.g., from lac, kermes or cochineal).

\section{Blue dye}

Specimen 10050 contains a blue-dyed yarn and specimen 10141 contains a green yarn, greens typically being produced by dyeing with a yellow and then top dyeing with a blue (or vice versa). The only natural blue dye is indigotin, which is produced by a number of plants $[9,10]$. Figures 3B and 4 in the green of 10141 and blue of 10050, respectively, both show the presence of indigotin and significant amounts of its isomer, indirubin. Indirubin, with an absorption maximum of about $550 \mathrm{~nm}$, has a more purple hue than indigotin, which has a maximum at about $610 \mathrm{~nm}$.

Interestingly, both of these specimens also have peaks corresponding to what we have termed "pseudoindirubin," because it has absorption maxima at both $550 \mathrm{~nm}$ (like indirubin) and $440 \mathrm{~nm}$ (Figures $3 \mathrm{~B}$ and 4). We have

Table 2 Types and probable sources of dye components found in Chehrabad textile yarns

\begin{tabular}{|c|c|c|c|c|}
\hline Specimen & Color & Dye(s) found & Dye type & Probable plant \\
\hline \multirow[t]{2}{*}{10031} & Red (Figure 2) & Alizarin (major) & Anthraquinone & Madder (Rubia tinctorum) \\
\hline & & Purpurin & & \\
\hline \multirow[t]{10}{*}{10050} & Red & Alizarin (major) & Anthraquinone & Madder (Rubia tinctorum) \\
\hline & & Purpurin & & \\
\hline & Blue (Figure 4) & Indigotin & Indigoid & Woad? (Isatis tinctoria?) \\
\hline & & Indirubin & & \\
\hline & & "Pseudoindirubin" & & \\
\hline & Yellow-1 (Figure 5) & Quercetin 3-O-sulfate & Flavonol & Tamarisk (Tamarix sp.) \\
\hline & & Quercetin 3-O-glucuronide & & \\
\hline & & Other flavonols and derivatives & & \\
\hline & & Ellagic acid & & \\
\hline & White & None & Undyed & None \\
\hline \multirow[t]{10}{*}{10141} & Red & Alizarin (major) & Anthraquinone & Madder (Rubia tinctorum) \\
\hline & & Purpurin & & \\
\hline & Green (Figure 3B) & Indigotin & Indigoid (blue part) & Woad? (Isatis tinctoria?) \\
\hline & & Indirubin & & \\
\hline & & "Pseudoindirubin" & & \\
\hline & & Quercetin 3-O-glucuronide & Flavonol (yellow part) & Unknown (Same as for yellow-2) \\
\hline & & (Other 3-O-flavonol glycosides) & & \\
\hline & Yellow-2 (cf. Figure 3A) & Quercetin 3-O-glucuronide & Flavonol & Unknown \\
\hline & & (Other 3-O-flavonol glycosides) & & \\
\hline & White & None & Undyed & None \\
\hline
\end{tabular}




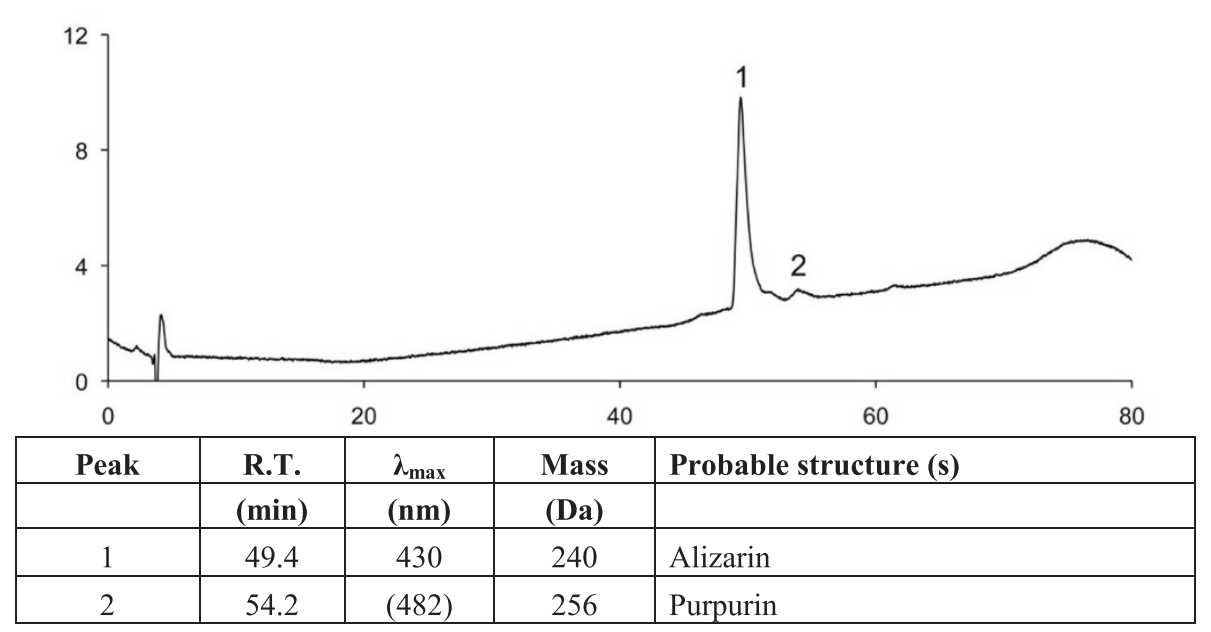

Figure 2 Reversed phase HPLC profile of extract of the red yarn in specimen 10031 monitored at $450 \mathrm{~nm}$; the y-axis units are milli-absorbance units (mAU), the $\mathbf{x}$-axis, minutes. The red yarns in specimens 10050 and 10141 have essentially the same profiles.

seen this substance in a number of ancient textiles and also in a modern sample of woad, and suspect that it may be a marker for woad (Isatis tinctoria L.), which is native to the north temperate zones from Europe to China and was used there until the introduction of Indian indigo (Indigofera spp.) in about the 17th century $[9,10]$. Mass measurements show that "pseudoindirubin" is not the indirubin isomer, isoindigotin [11]. We are currently trying to characterize it.

In addition, both indigo-containing specimens contain very small amounts of alizarin (not visible in Figures 3 and 4). Whether this arises from contamination by neighboring red fibers, to madder added to the dye vat to aid fermentation [9] or to madder added purposely to darken the blue dye, we do not know. However, we have seen this phenomenon before in other ancient textile fibers.

\section{Yellow dyes}

Of all the primary colors, yellow has the greatest number of natural sources. This study revealed that the yellow dyes in specimens 10050 and 10141 are flavonol dyes, though they came from different plant sources. Although flavone dyes (e.g., from weld, Reseda luteola L.) have been widely used in recent centuries, especially in Europe, because the aglycones, e.g., luteolin, are light-fast, flavonol (3-hydroxyflavone) dyes were also commonly used. Flavonols such as quercetin are fairly rapidly decomposed by light and oxygen [12], but we have shown $[7,13]$ that if the 3-hydroxy group is conjugated with a sugar or other moiety, it remains relatively light-fast.

The yellow fibers of specimen 10050 were colored with a dye that contains conjugates of flavonols, primarily of quercetin. We refer to this as yellow-1. All of them are substituted on the 3-hydroxyl group, as can be ascertained from their UV-maxima in the region 350$354 \mathrm{~nm}$. The largest peak is quercetin 3-O-sulfate (peak 4 in Figure 5). Ion extraction of the mass spectral data for this peak shows not only an M-1 peak of $381 \mathrm{Da}$ for quercetin sulfate, but also the fragment ion of M-1 = 301 for quercetin. Furthermore, treatment of an extract of 10050 with $\mathrm{HCl}$ yields almost entirely quercetin (data not shown). It will also be noted in Figure 5 that there is a large amount of quercetin (peak 8) present. However, this is probably an artifact of age or handling of the textile because a different sample of the same textile analyzed a few years earlier did not have as large a quercetin peak, although it did have the large quercetin sulfate peak. Flavonoid sulfate esters are much less stable than glycosides and are rather easily hydrolyzed to their aglycones (ref. [6] and unpublished observations).

Flavonoid sulfates are relatively rare among the 8000 or so known flavonoids [14], and rarer still as components of yellow dyes. In fact, the only previous report of flavonoid sulfate dyes comes from our own laboratory for some pre-Colombian Andean textiles [15]. Figure 5 shows that the major colorant in the dye, yellow-1 (from specimen 10050), is quercetin 3-O-sulfate. However, another marker, not usually seen in yellow dyes, is ellagic acid, which is commonly associated with tannins. The presence primarily of flavonol sulfates and of ellagic acid, and consideration of the plants that might have grown in the arid environment of the Chehrabad salt mine 2000 years ago, led us to suspect that the dyestuff may have been a species of tamarisk (Tamarix sp.). In fact, tamarisk grows near the Chehrabad mine today, though we have not been able to identify the species so far. 

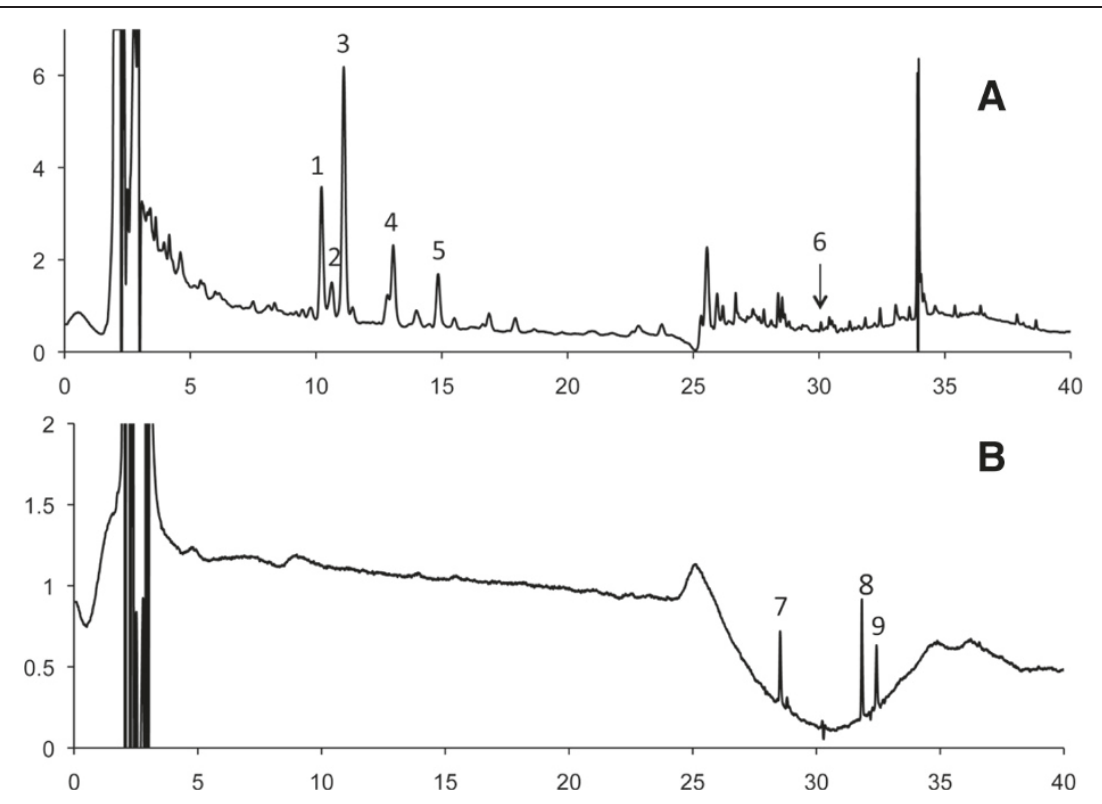

\begin{tabular}{|c|c|c|c|l|}
\hline Peak & R.T. & $\lambda_{\max }$ & Mass & Probable structure (s) \\
\hline & $\mathbf{( m i n )}$ & $(\mathbf{n m})$ & $\mathbf{( D a})$ & \\
\hline 1 & 10.2 & 354 & 464 & Quercetin 3-O-glucoside \\
\hline 2 & 10.6 & 340 & 464 & Unidentified flavonoid \\
\hline 3 & 11.1 & 353 & 478 & Quercetin 3-O-glucuronide \\
\hline 4 & 13.1 & 353 & 434 & Quercetin 3- $O$-pentoside? \\
\hline 5 & 14.9 & 347 & 448 & Kaempferol 3- $O$-glucoside? \\
\hline 6 & 30.4 & 430 & 240 & Alizarin (seen in 450-nm scan) \\
\hline 7 & 28.5 & 445,554 & 501 & Pseudoindirubin \\
\hline 8 & 31.8 & 611 & 262 & Indigotin \\
\hline 9 & 32.4 & 550 & 262 & Indirubin \\
\hline
\end{tabular}

Figure 3 Reversed phase HPLC profile of extract of the green yarn in specimen 10141 monitored at $350 \mathrm{~nm}$ (profile A) and at $600 \mathrm{~nm}$ (profile B); the $\mathbf{y}$-axis units are $\mathbf{m A U}$, the $\mathbf{x}$-axis, minutes. Alizarin (which is red) is not seen in these profiles, but it does appear when the elution is monitored at $450 \mathrm{~nm}$ (cf. as in Figure 2). The large peak at about $34 \mathrm{~min}$ in profile $\mathbf{A}$ is a non-flavonoid artifact.

Consequently we analyzed a number of species of Tamarix and detected quercetin 3-O-glucuronide and a variety of flavonol sulfates in all, and ellagic acid in nearly all, species (Table 3 ). Few contained the glycosides (e.g., derivatives of glucose and rhamnose) found in most other flavonol dyes [7]; thus the Tamarix flavonoids are rather distinctive. Most of the species in Table 3 were herbarium specimens, but a few were collected by nontaxonomists, including the authors. It is not possible to draw conclusions from the precise relative peak sizes of the components because these are dependent on a variety of environmental conditions, as well as the history and handling of samples. From the data in Table 3, it is difficult to decide whether any of the species listed was used to produce the yellow-1 dye in 10050, but Tamarix ramosissima Ledeb (note that $T$. pentandra Pallas is a synonym for $T$. ramosissima [16]), which grows commonly in many places, including Iran, is a reasonable possibility. There are also reports $[17,18]$ of tamarisk having been used as a dyestuff for yellow and for black, due, presumably, to the presence of both flavonoids and tannins, respectively, but it seems to have been used most frequently for black.

We also analyzed herbarium specimens of several other plants reported to contain flavonoid sulfates [14] and to grow in Iran [16], but their HPLC profiles did not resemble those of the of the textile specimens and none contained ellagic acid (data not shown).

The composition of flavonols found in specimen 10141 (yellow-2) is completely different from that found for yellow-1, although it is clear that the same yellow was used for both the yellow and green yarns in this specimen (cf. Figure 3A). The primary components have M-1 values of $463 \mathrm{Da}, 477 \mathrm{Da}, 433 \mathrm{Da}$ and $447 \mathrm{Da}$, the first two of which appear to be quercetin 3-O-glucoside and quercetin 


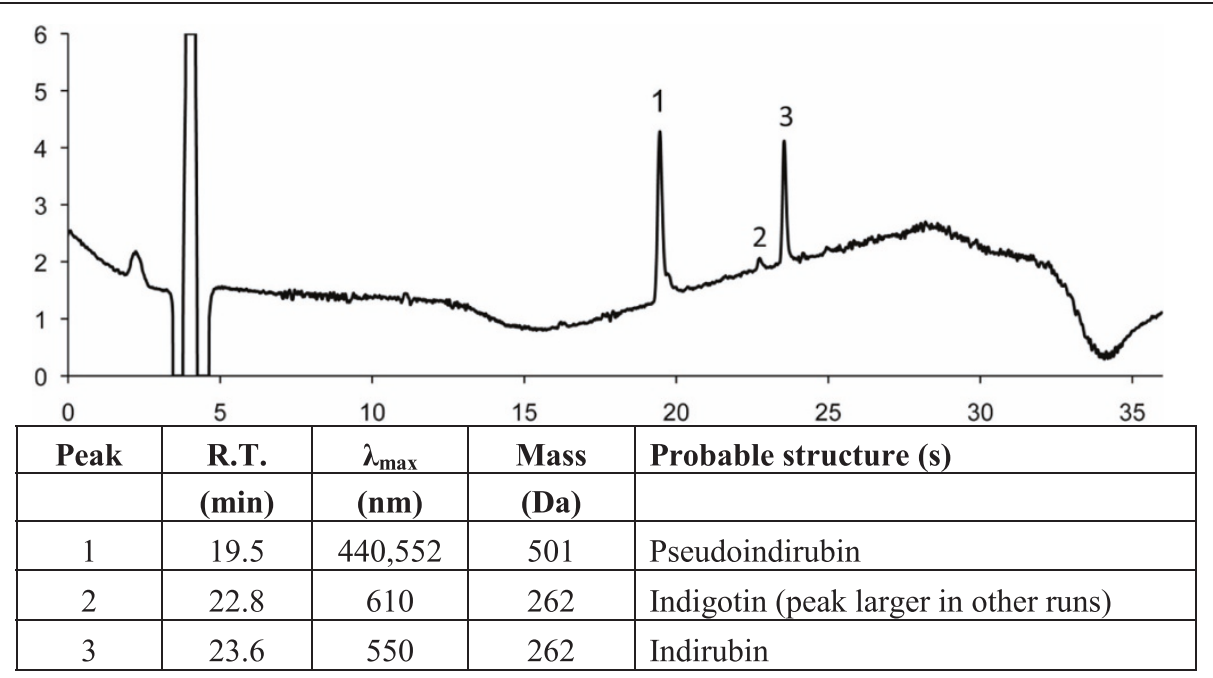

Figure 4 Reversed phase HPLC profile of extract of the blue yarn in specimen 10050 monitored at $600 \mathrm{~nm}$; the $y$-axis units are mAU, the $x$-axis, minutes.

3-O-glucuronide, respectively. There seem to be no appreciable amounts of flavonol sulfates. In any event, the pattern does not match the compositions of anything in our library of some 200 yellow dyestuffs, so the only thing we can conclude is that yellow-2 is not the same as yellow1 or any of the other more common flavonoid yellows.
Dyed textile fragments dating back to the Bronze Age have also been discovered in the salt mines at Hallstatt, Austria. Preliminary analysis of these dyes [19] suggests that the yellow dyes are of a different origin, which is not surprising because the flora of this part of the world is quite different from that of Iran,

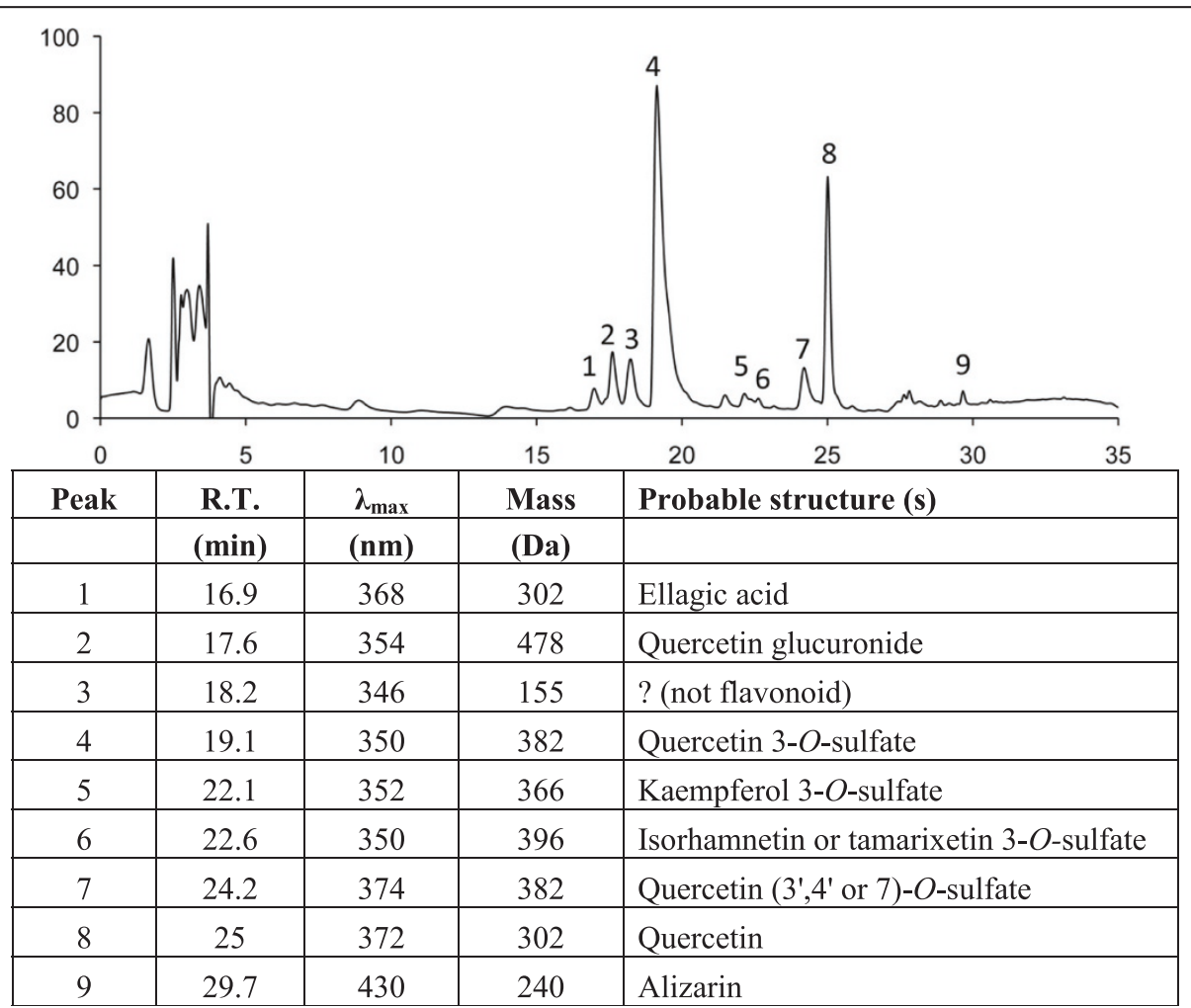

Figure 5 Reversed phase HPLC profile of extract of the yellow yarn in specimen 10050 monitored at $350 \mathrm{~nm}$; the $y$-axis units are mAU, the $\mathrm{x}$-axis, minutes. 
Table 3 Summary of analytical data for various species of Tamarix and for the yellow dye in specimen 10050 from Chehrabad

\begin{tabular}{|c|c|c|c|c|c|c|c|c|c|c|c|c|c|c|c|c|c|c|c|}
\hline \multirow[b]{2}{*}{ Species } & \multicolumn{13}{|c|}{ Flavonol conjugates/mass } & \multicolumn{6}{|c|}{ Flavonol aglycones/mass } \\
\hline & $\begin{array}{l}\text { Source of } \\
\text { specimen }\end{array}$ & $\begin{array}{l}\text { Ell }^{1} \\
302\end{array}$ & $\begin{array}{l}\text { QueGlr } \\
478\end{array}$ & $\begin{array}{l}\text { QueRha } \\
448\end{array}$ & $\begin{array}{l}\text { QueSO }_{3} \\
382\end{array}$ & $\begin{array}{l}\text { KaeGlr } \\
462\end{array}$ & $\begin{array}{l}\mathrm{KaeSO}_{3} \\
366\end{array}$ & $\begin{array}{l}\mathrm{IrhSO}_{3} \\
396\end{array}$ & $\begin{array}{l}\text { KaeRha } \\
432\end{array}$ & $\begin{array}{l}\mathrm{RhmSO}_{3} \\
396\end{array}$ & $\begin{array}{l}\mathrm{RhzSO}_{3} \\
410\end{array}$ & $\begin{array}{l}\mathrm{KadSO}_{3} \\
380\end{array}$ & $\begin{array}{l}\text { QueSO }_{3}^{2} \\
382\end{array}$ & $\begin{array}{l}\text { Que } \\
302\end{array}$ & $\begin{array}{l}\text { Kae } \\
286\end{array}$ & $\begin{array}{l}\text { Irh/Tam } \\
316\end{array}$ & $\begin{array}{l}\text { Rha } \\
316\end{array}$ & $\begin{array}{l}\text { Kad } \\
300\end{array}$ & $\begin{array}{l}\text { Rhz } \\
330\end{array}$ \\
\hline T. bungei Boiss. & Uzbekistan & $x$ & $x x x$ & $x x$ & & & $x$ & & $x$ & $x x$ & $x x$ & $x x$ & & & & & & & \\
\hline Tamarix sp. & Uzbekistan & $?$ & $x x$ & $x \mathrm{x}$ & & & $x$ & $x x x$ & $x x$ & & & $x x$ & & $x^{3}$ & $x x^{3}$ & $x x^{3}$ & & $x^{3}$ & \\
\hline Tamarix sp. & Gansu, China & $?$ & $x x x$ & & & & $x$ & $x x x$ & & & $x$ & $x$ & & & & & & & \\
\hline Tamarix sp. & Utah, USA & $x$ & $x x x$ & & $x$ & $x x$ & $\mathrm{x}$ & $x$ & & & $x$ & $x$ & & $x x^{3}$ & $x x^{3}$ & $x^{3}$ & & $x^{3}$ & $x^{3}$ \\
\hline T. ramosissima Ledeb. & Iran & $x$ & $x x x$ & & $x$ & $x$ & $x$ & $x$ & & & & & & $x x x$ & $x$ & $x$ & & & \\
\hline T. pentandra Pallas ${ }^{4}$ & Iran & $x$ & $x x x$ & & $x x$ & $x$ & & $x$ & & & & & trace & $x x x$ & $?$ & $?$ & & & \\
\hline T. articulata Vahl & Iran & $x x$ & $x x$ & & & & & $x$ & & & $x$ & & & & & $?$ & $?$ & $?$ & $?$ \\
\hline T. articulata Vahl & Russia & $x$ & $x$ & & & & & $x$ & & & & & & & & & & & \\
\hline T. gallica L. & Iraq & $x x$ & $x x$ & & $x x$ & & $x$ & & & $x x$ & & $x x x$ & & & & & & $x$ & \\
\hline T. gallica L. & Saudi Arabia & $x$ & $x$ & & $x$ & $x$ & & $x x$ & & & $x$ & $x x x$ & & & & & & $x$ & \\
\hline T. florida Bge. & Iran & $\mathrm{x}$ & $x$ & & $x x$ & $x x$ & $x x$ & & & $x x$ & & $x$ & & & & & & $x x$ & \\
\hline $10050-1^{5}$ & Iran & $x$ & $x$ & & $x x x$ & & & & & & & & $x$ & $x$ & & & & & \\
\hline $10050-2^{5}$ & Iran & $\mathrm{x}$ & $x$ & & $x x x$ & & & trace & & & & & $x$ & $x x$ & & & & & \\
\hline
\end{tabular}

Unless otherwise indicated, all glycosides and sulfates are attached at the flavonol 3-hydroxy group. Flavonol derivatives are listed, from left to right, in order of their elution from a reversed phase HPLC column. The number of " $x$ " marks indicates the relative peak size, with xxx being the most prominent, $x x$ less than about $50 \%$ of xxx or one of two or more peaks of similar size, and $x$ significantly smaller, but present. ${ }^{1}$ Abbreviations: Ell, ellagic acid; Que, quercetin; Kae, kaempferol; Irh, isorhamnetin; Rhm, rhamnetin; Rhz, rhamnazin; Kad, kaempferide; Tam, tamarixetin; Glr, glucuronide; Rha, rhamnoside; SO${ }_{3}$, sulfate ester. ${ }^{2}$ Not 3-O-sulfate.

${ }^{3}$ observed after hydrolysis by $\mathrm{HCl}$.

${ }^{4} T$. pentandra $=T$. ramosissima. Both of these were very old ( 100 years) herbarium specimens, in which some quercetin sulfate may have hydrolyzed to quercetin.

${ }^{5}$ Two different samples of the same object. 10050-1 was obtained about two years earlier than 10050-2. 


\section{Conclusions}

The red and blue fibers of the objects analyzed were dyed with madder (specifically, Rubia tinctorum) and indigo (possibly woad, Isatis tinctoria), respectively, both of which plants grow widely and have been used for dyeing in Central Asia and environs for centuries.

Two yellow dyes, both flavonol-type plant dyes, were identified in two different objects. One appears to be from a species of tamarisk (Tamarix sp.), a plant that grows widely throughout the world, including the vicinity of the Chehrabad salt mine. This is the first evidence based on analytical data that tamarisk was used as a dyestuff. The plant that provided the second yellow dye is unknown at present.

All of the dyes used seemed to have been derived from plants that were probably locally available and easy to obtain. This is consistent with their having been found in a work site, where one would not expect to encounter clothing colored with expensive imported dyes.

The identification of these dyes does not (and cannot) provide any information about the age of the objects, however.

\section{Abbreviations}

HPLC: High performance liquid chromatography; UV: Ultraviolet.

\section{Competing interests}

The authors declare that they have no competing interests.

\section{Authors' contributions}

CM and XZ carried out the analytical work. AA provided the textile samples and information about them. RL prepared the manuscript and oversaw the entire project. All authors read and approved the final manuscript.

\section{Authors' information}

The submitting author (RL) is a Professor Emeritus of Chemistry at Boston University and has devoted the past 10 years to the development and use of techniques for the analysis of dyes in textiles of historical and cultural interest.

\section{Acknowledgments}

We would especially like to thank Dr. Hashem Akhlaghi, Islamic Azad University, Sabzevar, Iran, for logistical support, and Dr. David Boufford of the Harvard University Herbaria, Dr. Ivan Maltsev of the Industrial-Research Center "Botany", Tashkent, Uzbekistan, and Ann Kelsey, University of Utah, for providing or helping to obtain specimens of tamarisk and other plants.

\section{Author details}

'Department of Chemistry, Boston University, Boston, MA 02215, USA

${ }^{2}$ Archaeological Museum of Zanjan, Zanjan, Iran.

Received: 14 July 2014 Accepted: 8 September 2014

Published online: 30 September 2014

\section{References}

1. Aali A, Stöllner T, Abar A, Rühli F: The salt men of Iran: the salt mine of Douzlakh, Chehrabad. Archäologisches Korrespondenzblatt 2012, 42:61-81.

2. Aali A, Abar A, Boenke N, Pollard M, Rühli R, Stöllner T: Ancient salt mining and salt men: the interdisciplinary Chehrabad Douzlakh project in north-western Iran. Antiquity 2012, 86: [http://antiquity.ac.uk/projgall/aali333/]

3. Pollard AM, Brothwell DR, Aali A, Buckley S, Fazeli H, Hadian Dehkordi M, Holden T, Jones AKG, Sholouhi JJ, Vatandoust R, Wilson AS: Below the salt: a preliminary study of the dating and biology of five salt-preserved bodies from Zanjan Province, Iran. Iran 2008, 46:135-150.
4. Mouri C, Laursen R: Identification and partial characterization of C-glycosylflavone markers in Asian plant dyes using liquid chromatography-tandem mass spectrometry. J Chrom A 2011, 1218:7325-7330.

5. Zhang X, Laursen RA: Development of mild extraction methods for the analysis of natural dyes in textiles of historical interest using LC-diode array detector-MS. Anal Chem 2005, 77:2022-2025

6. Markham KR: Techniques of Flavonoid Identification. New York: Academic; 1982:36-39.

7. Mouri C, Mozaffarian V, Zhang X, Laursen RA: Characterization of flavonols in plants used for textile dyeing and the significance of flavonol conjugates. Dyes Pigments 2014, 100:135-141.

8. Mouri C, Laursen R: Identification of anthraquinone markers for distinguishing Rubia species in madder-dyed textiles by HPLC. Microchim Acta 2012, 179:105-113.

9. Cardon D: Natural Dyes: Sources, Traditions, Technology and Science. London: Archetype; 2007:335-408.

10. Balfour-Paul J: Indigo. London: British Museum Press; 1998:89-114.

11. Maugard T, Enaud E, Choisy P, Legoy MD: Identification of an indigo precursor from leaves of Isatis tinctoria (woad). Phytochemistry 2001, 58:897-904

12. Ferreira ESB, Quye A, McNab H, Hulme AN: Photo-oxidation products of quercetin and morin as markers for the characterization of natural flavonoid yellow dyes in ancient textiles. Dyes History Archaeol 2002, 18:63-72

13. Zhang $X$, Cardon D, Cabrera JL, Laursen RA: The role of glycosides in the light-stabilization of 3-hydroxyflavone (flavonol) dyes as revealed by HPLC. Microchim Acta 2010, 169:327-334.

14. Barron D, Varin L, Ibrahim RK, Harborne JB, Williams CA: Sulphated flavonoids-an update. Phytochem 1988, 27:2375-2395.

15. Zhang X, Boytner R, Cabrera JL, Laursen RA: Identification of yellow dye types in pre-Columbian Andean textiles. Anal Chem 2007, 79:1575-1582

16. Mozaffarian V: A Dictionary of Iranian Plant Names. Tehran: Farhang Moaser 1998:533.

17. Perkin AG, Everest AE: The Natural Organic Colouring Matters. London: Longmans, Green and Co; 1918:455.

18. Schweppe H: Handbuch der Naturfarbstoffe. Hamburg: Nikol; 1993:485.

19. Joosten I, van Bommel MR, Hofmann-de Keijzer R, Reschreiter H: Micro analysis on Hallstatt textiles: colour and condition. Microchim Acta 2006, 155:169-174.

doi:10.1186/s40494-014-0020-3

Cite this article as: Mouri et al:: Analysis of dyes in textiles from the Chehrabad salt mine in Iran. Heritage Science 2014 2:20.

\section{Submit your manuscript to a SpringerOpen ${ }^{\odot}$ journal and benefit from:}

- Convenient online submission

- Rigorous peer review

- Immediate publication on acceptance

- Open access: articles freely available online

- High visibility within the field

- Retaining the copyright to your article

Submit your next manuscript at $>$ springeropen.com 